\title{
Effects of Environmental Enrichment on Some Growth, Carcass, and Behavioral Parameters of Native Turkish Geese
}

\author{
Atilla Taskin ( $\sim$ taskinatilla@gmail.com ) \\ Kirsehir Ahi Evran Universitesi https://orcid.org/0000-0001-5897-2062 \\ Ufuk Karadavut \\ Karabuk University Faculty of Medicine: Karabuk Universitesi Tip Fakultesi \\ Esma Dogan \\ Kirsehir Ahi Evran Universitesi \\ Demirel ERGUN \\ Kirsehir Ahi Evran Universitesi
}

\section{Research Article}

Keywords: Goose, captive, welfare, behaviour, environmental enrichment

Posted Date: January 27th, 2022

DOI: https://doi.org/10.21203/rs.3.rs-1211703/v1

License: (a) (i) This work is licensed under a Creative Commons Attribution 4.0 International License. Read Full License 


\section{Abstract}

The aim of the study is to examine the performance and carcass characteristics and some behavioral parameters of geese reared in the areas created by using some objects for environmental enrichment (EE) purpose. For this purpose, a total of 72 one-day-old goose goslings of both sexes were used. Geese were accommodated collectively for the first four weeks, then they were divided in three groups in 3 repetitions according to the EE applications and these were expressed as control (C), broom (B), and mirror (M). At the end of 14th week, live weight ( $L W)$, beak length $(B L)$, wing length $(W L)$, head diameter $(H D)$, foot width (FW), body temperature (BT), warm carcass (WC), and cold carcass (CC) weights as well as warm and cold $\mathrm{pH}$ values $(\mathrm{WpH} \& \mathrm{CpH})$, and tonic immobility duration (TID) of the groups were measured. Responses presented during the $\mathrm{TI}$ test were expressed as non-responses (NR), medium responses (MR), and high responses (HR). Among the groups, group $M$ had the lowest value $(110.08 \pm 10.69 \mathrm{~s})$ in terms of TID $(P>$ 0.05). Differences in terms of NR, MR, and HR were significant $(P>0.05)$. The differences between the groups were not statistically significant in terms of the other characteristics $(P<0.05)$. As a result, it was determined that geese reared by using the EE objects were affected by such environments, however, there were differences between the groups in terms of fear and stress parameters without having any negative effects on yield.

\section{Introduction}

Geese are herbivorous animals having an important role in Anatidae family (Taskin et al., 2020a; Taskin et al., 2020b). Their feed conversion ratios, resistance to diseases, and adaptation skills are high (Karadavut and Taskin 2014). Geese are generally reared for their eggs, livers, and feathers (Boz et al., 2017). In addition, goose meat is a qualified protein source that is rich in unsaturated fatty acids and essential fatty acids (Schmid, 2011; Ergun et al., 2020).

Morphological, physiological, and behavioral changes occur in living beings during growth and development. Genotype and environment are the most important factors affecting growth and development (Fanatico et al., 2007; Karadavut et al., 2017). Various changes are observed during growth and development of geese. For example, while the live weight increase, one of these changes, is rapid in the first 4 weeks, it slows down in the subsequent weeks (Saatci et al., 2011; Kokoszynski et al., 2014). Environmental factors affect both the yield and behavioral properties of geese in growth and development stages (Schmidt-Nielsen, 1997). In addition, it is reported that increase of behaviors and wealth in poultry have contributed to the improvement of biological functions (Regmi et al., 2016; Gebhardt-Henrich et al., 2017). Environmental enrichment methods can be used to reduce the effect of environmental factors or turn them into an advantage, especially in intensive goose rearing. In this way, geese both have an increased quality of life and showed normal behaviors.

Environmental enrichment can be defined as the rearrangement of the home range of living beings by using various objects (Belz et al., 2003). For this purpose, various visuals, sounds, structures, plastic materials, and odor are used as essential enrichment instruments in the coops (Branch et al., 2015; 
Fernandes et al., 2015; Yildirim and Taskin., 2017; Taskin and Karadavut, 2017). In the new environments established by using these instruments, it is provided to have the animals feel as if they are in their own nature and show species-specific behaviors freely. This also increases the wealth level of the animals (Van de Weerd and Day, 2009).

In the present study, the objects broom and mirror were used for environmental enrichment (EE). Thus, its aim is to investigate the possible effects of environmentally enriched media on the live weight (LW), wing length (WL), head diameter (HD), beak length (BL), foot width (FW), tonic immobility durations (TID), tonic immobility responses (TIR), body temperature (BT), cold carcass (CC), warm carcass (WC), $c 0 l d p H(C p H)$, and warm $\mathrm{pH}(\mathrm{WpH})$ of geese.

\section{Material And Methods}

\section{Experimental site, animals, and management}

The study was conducted at Poultry Research Unit of Kirsehir Ahi Evran University Faculty of Agriculture Department of Animal Science (39 $8^{\prime} 45^{\prime \prime} \mathrm{N}$ and $\left.34^{\circ} 9^{\prime} 34^{\prime \prime} \mathrm{E}\right)$ upon the approval of Kirsehir Ahi Evran University Animal Experiments Local Ethics Committee (dated 27.01.2016 and numbered 01/12).

In the study, a total of 72 goose goslings of both sexes (native Turkish geese) which were obtained from Breeding Goose Facility of Yozgat Bozok University were used. Natural photoperiod was applied for the geese. Geese were fed ad libitum. They were fed with a feed containing $28 \% \mathrm{HP}$ and $2800 \mathrm{kcal} / \mathrm{kg} \mathrm{ME}$ for the first two weeks and a feed containing 20\% HP and $3000 \mathrm{kcal} / \mathrm{kg} \mathrm{ME}$ between 4th and 14th weeks (NRC, 1994). Geese were kept in a climate-controlled environment ( $37^{\circ} \mathrm{C}$ and $60 \%$ humidity) for the first week. Then, the temperature was gradually reduced to room temperature. The geese were kept together until the end of 4th week. Then, the goose goslings were identified individually by attaching numbered anklets to their feet, and all processes were carried out over these numbers. In the study, biosafety rules were followed. Wood shavings was used as the litter material. The litters in the pens were cleaned weekly and replaced with a new one.

\section{Environmental enrichment}

Objects used for environmental enrichment were specially designed by considering previous studies conducted on poultry (Yildirim and Taskin, 2017). In the study, broom and mirror were used to promote the pecking behaviors and locomotor activities of geese. These objects were $20 \times 10 \mathrm{~cm}$ tetrahedral mirrors (Flotal EN 1036) and green (Uctem LUX004) brooms with red sticks. Except control group, two of each object were placed in each cage. The objects were hung with ropes hanging down the cage ceiling as to have a ground clearance of $30 \mathrm{~cm}$. Considering the growth of the geese and their interaction with the objects, the height of the objects was gradually increased by $5 \mathrm{~cm}$ every two weeks. 
Geese were randomly divided in three groups having similar mean live weights at the end of 4th week. They were placed in nine partitions in the sizes of $1 \times 2.5 \mathrm{~m}$, with eight geese in each. Control (C), broom (B), and mirror (M) groups were developed to have three replications (8 per replication, the group total of 24 geese, and general total of 72 geese).

\section{Data collection}

Morphological traits were determined every 7 days between 4 th and 14 th weeks. The tarits were determined individually and evaluated in group. Geese were allowed to feed and water until 12 hours before weighing. Live weight (LW) was determined individually by using an electronic balance with precision of $0.01 \mathrm{~g}$ and evaluated in group. Beak Length $(\mathrm{BL})$ was defined as the upper beak length and the length between the tip of the beak and the head length was measured. Wing length (WL) was found by measuring the distance between the 3rd carpal bone and caput humeri (Szabone Willin et al.,1997). Head diameter (HD) was determined by using a tape measure (Saatci and Tilki 2007). Goose feet have four toes (one back short toe, front three long toes). The three toes facing forward are palmately webbed. Measurement of the foot width (FW) was calculated by measuring the width between the lateral toes through a digital caliper after they were opened wide on the ground. Body temperature (BT) was measured by using a digital thermometer. Thermocouple of digital thermometer was placed in the cloak and the value measured was read after $30 \mathrm{~s}$.

Geese were laid on the back on the table by keeping their heads down. The observer slightly applied pressure on the chest of the goose for $15 \mathrm{~s}$ with his hand, then removed his hand and observed from a distance of $1 \mathrm{~m}$. The application was repeated for geese that stood up or turned aside within $10 \mathrm{~s}$. Tonic immobility durations (TID) of the geese, which did not stand up within $10 \mathrm{~s}$, were measured by using a chronometer. If no $\mathrm{Tl}$ reaction occurred after 5 repeated interventions, the relevant goose was scored as 0 . In addition, geese were evaluated in three groups according to their responses for TI stimulation. Of the geese, those that only showed $\mathrm{TI}$ reaction, those that showed $\mathrm{TI}+$ sound, and those that $\mathrm{TI}+$ defecation were grouped as non-response (NR), medium-response (MR), and high-response (HR), respectively and they were expressed as percent (Taskin et al., 2018).

In the study, four geese with a body weight close to the mean were randomly selected from each replication (36 geese in total). A 12-hr fasting period was applied before slaughtering and water was given ad libitum. Their live weights before slaughtering were determined. Geese slaughtered by using a knife were kept in $55-60^{\circ} \mathrm{C}$ water for 5 minutes and their feather was plucked by using a plucking machine. Their warm carcass (WC), cold carcass (CC), warm pH (WpH), and cold pH (CpH) values were measured. While warm measurements were conducted during slaughtering, cold measurements were done after the carcasses were waited at $4^{\circ} \mathrm{C}$ for 24 hours. Measurements were performed from the chest (musculus pectoralis major) and thigh areas (biceps femoris) by using a $\mathrm{pH}$ meter and their mean values were recorded (Tůmová and Uhlírová 2013) . 


\section{Statistical analysis}

In the study, F test was applied in order to determine whether the change among the characters was statistically significant. Duncan's multiple range test was applied to determine which variable(s) caused the difference in statistically significant groups. Thus, the differences were sensitively evaluated. In addition, regression analysis showing the effects of the emphasized characters on live weight and correlation analysis showing the relations between the characters were performed. In the study, SPSS 24 $\checkmark$ statistical package program was used.

\section{Results}

In the 14th week of the study, LW values of geese were measured by using a precision balance (Fig. 1). The difference between the groups was statistically insignificant $(P<0.05)$. According to the treatment groups, LW was found as $4.211 \pm 0.21 \mathrm{~kg}, 4.216 \pm 0.24 \mathrm{~kg}$, and $4.210 \pm 0.22 \mathrm{~kg}$, respectively for $C, B$, and $M$.

According to the regression analysis, HD had the highest effect on LW for group $C$ (1.93). While HD value had the highest negative value in group $B$, it had the highest positive value for group $M$. It can be asserted that HD was the character that affected the live weight at the highest rate.

$\mathrm{C}$ for the regression equation is $\mathrm{LW}=15.20+1.93 \mathrm{HD}+0.61 \mathrm{BL}-1.38 \mathrm{FW}-0.30 \mathrm{BT}+0.059 \mathrm{WL}$

$\mathrm{B}$ for the regression equation is $\mathrm{LW}=39.01-4.80 \mathrm{HD}+0.75 \mathrm{BL}-1.45 \mathrm{FW}-0.34 \mathrm{BT}+0.16 \mathrm{WL}$

$M$ for the regression equation is $L W=-41.10+4.26 \mathrm{HD}+0.23 \mathrm{BL} 2-0.18 \mathrm{FW}+0.65 \mathrm{BT}+0.027 \mathrm{WL}$

At the end of 14th week, the difference between $B L$ values of the groups was statistically insignificant ( $P$ $<0.05$ ). According to the treatment groups, $B L$ measurements were found as $7.38 \pm 0.22 \mathrm{~cm}, 7.35 \pm 0.19$ $\mathrm{cm}$, and $7.36 \pm 0.23 \mathrm{~cm}$, respectively for $\mathrm{C}, \mathrm{B}$, and $\mathrm{M}$ (Fig. 2).

At the end of 14th week, WL values were found (Fig. 3). The difference between the groups was statistically not significant $(P<0.05)$. The highest value was found in group $B(61.39 \pm 2.49 \mathrm{~cm})$ and the lowest value in group $M(58.71 \pm 2.96 \mathrm{~cm})$.

HD values of the groups were determined (Fig. 4). The differences between the groups were statistically insignificant $(P<0.05)$.

Waterfowl are generally totipalmate. Palmates can be morphologically classified in four groups as palmate, semipalmate, totipalmate, and lobate. Foot structure of geese is palmate, which is mostly common (Tokita et al., 2020). The FW of the geese were measured with the help of calipers at the end of the 14th week (Fig. 5). However, the difference between the groups was statistically insignificant $(\mathrm{P}<$ $0.05)$. According to the treatment groups, $F W$ was measured as $10.91 \pm 0.09 \mathrm{~cm}, 10.90 \pm 0.19 \mathrm{~cm}$, and $10.90 \pm 0.09 \mathrm{~cm}$, respectively for $C, B$, and $M$. 
BT values of the groups were determined. The difference between the groups was statistically insignificant $(P<0.05)$. According to the treatment groups, body temperature values were measured as $40.21 \pm 0.29^{\circ} \mathrm{C}, 40.93 \pm 0.19^{\circ} \mathrm{C}$, and $40.20 \pm 0.44^{\circ} \mathrm{C}$, respectively for $\mathrm{C}, \mathrm{B}$, and M. However, according to the clustering analysis, BT showed a significant difference from other characters in all applications (Fig. 6). While BL and FW established a group in group C; LW, WL, and HD formed a separate group. For group $B$, BT and HD formed separate groups, while other properties took place in the similar group. Similarity was also observed in group $\mathrm{M}$.

According to the results of the correlation analysis, significant and positive correlations were found between HD and LW, between $B L$ and $L W$ and HD, between FW and LW, HD and $B L$, and between $W L$ and LW, HD BL and FW according to 0.01 for group C (Table 1). It can be seen that similar results with group $C$ were obtained based on the correlation analyses performed for groups B and M. Accordingly, in the study, it was seen that the correlations between the variables in the Table 1 did not cause a serious change according to the treatments.

Table 1

Correlations among some body measurements

\begin{tabular}{|c|c|c|c|c|c|c|}
\hline & & LW & HD & BL & FW & BT \\
\hline \multirow[t]{3}{*}{$H D$} & $C$ & $0.95^{\star \star}$ & & & & \\
\hline & $B$ & $0.88^{\star \star *}$ & & & & \\
\hline & $M$ & $0.95^{\star \star}$ & & & & \\
\hline \multirow[t]{3}{*}{$\mathrm{BL}$} & $C$ & $0.95^{\star \star}$ & $0.93^{\star *}$ & & & \\
\hline & $B$ & 0.96 ** & $0.85^{\star \star}$ & & & \\
\hline & $M$ & $0.97^{\star \star *}$ & $0.89 * *$ & & & \\
\hline \multirow[t]{3}{*}{ FW } & $C$ & $0.92 \star \star$ & $0.92^{\star \star}$ & $0.99 * \star$ & & \\
\hline & $B$ & $0.97^{\star *}$ & $0.83^{\star *}$ & $0.98 * *$ & & \\
\hline & $M$ & 0.94 ** & $0.88^{* *}$ & $0.99 * *$ & & \\
\hline \multirow[t]{3}{*}{ BT } & $C$ & -0.64 & -0.53 & -0.48 & -0.44 & \\
\hline & $B$ & $0.86^{\star}$ & 0.70 & 0.75 & $0.75^{\star}$ & \\
\hline & $M$ & -0.22 & -0.46 & -0.25 & -0.29 & \\
\hline \multirow[t]{3}{*}{ WL } & $C$ & $0.99 * *$ & $0.94 * \star$ & $0.97 \star \star$ & $0.94^{\star *}$ & -0.62 \\
\hline & $B$ & $0.99 * *$ & $0.91^{\star \star}$ & $0.95^{\star \star}$ & $0.96 * *$ & $0.86^{*}$ \\
\hline & $M$ & $0.98 * \star$ & $0.91^{\star *}$ & $0.98 * \star$ & 0.96 ** & -0.20 \\
\hline *: P & .0 & $P<$ & & & & \\
\hline
\end{tabular}


WC and $\mathrm{CC}$ weights of the groups were weighed and $\mathrm{pH}$ measurements were done (Fig. 7). According to the treatment groups, WC values were found as $2.30 \pm 0.34 \mathrm{~kg}, 2.29 \pm 0.41 \mathrm{~kg}$, and $2.31 \pm 0.38 \mathrm{~kg}$, respectively for $C, B$, and $M$. According to the treatment groups, $C C$ values were found as $2.25 \pm 0.63 \mathrm{~kg}$, $2.26 \pm 0.53 \mathrm{~kg}$, and $2.25 \pm 0.74 \mathrm{~kg}$, respectively for $\mathrm{C}, \mathrm{B}$, and $\mathrm{M}$. In a study, $\mathrm{WC}$ and CC values were stated as $1.96 \pm 0.45$ and $1.95 \pm 0.45$ (Akbas et al., 2020). Additionally, no statistical difference was found between the $\mathrm{pH}$ values.

$\mathrm{TI}$ is a good method for the measurement of stress, fear, and welfare levels in poultry. In addition, it is the best indicator of passive fear response in poultry. In the current study, according to the treatment groups, TI was measured as $122.03 \pm 11.27 \mathrm{~s}, 124.05 \pm 15,18 \mathrm{~s}$, and $110.08 \pm 10,69 \mathrm{~s}$, respectively for $\mathrm{C}, \mathrm{B}$, and $\mathrm{M}$ (Fig. 8). The difference between the groups was statistically significant $(P>0.05)$. Group M showed a TI reaction for a shorter period when compared to groups $C$ and $B$. This may be due to the fact that the mirror creates a crowd simulation without increasing the placement frequency. In addition, the mirror may have functioned for the geese to adapt to unexpected situations.

Of the geese, those that were only formed by TI without any additional response, those making sound, and those defecating, were grouped as NR, MR, and HR, respectively, and expressed as \% (Fig. 9). The difference between the groups was statistically significant $(P>0.05)$. Accordingly, $B$ treatment was the highest in group NR. In MR group, $C$ treatment that did not consist of an enrichment object was the highest. This may be caused by the fact that geese were unaccustomed to the unexpected conditions. While M treatment had relatively the highest rate in HR group, its low TI duration (Fig. 9) may be a phenomenon that should be emphasized.

\section{Discussion}

In a study conducted with geese having similar genotypes under free-range conditions, an average of $3.780 \mathrm{~kg} \mathrm{LW}$ was achieved in the 28th week (Boz et al., 2019). In a study conducted 32-week-old white and multicolor geese reared in family enterprises, this value was reported to be $3.840 \mathrm{~kg}$ and $3.220 \mathrm{~kg}$ in white and multicolor geese (Yakan et al., 2012). In another study conducted with native geese that were grouped according to their feather color, it was reported that brown multicolor geese reached the highest live weight $(3.797 \mathrm{~kg})$ at the end of 32nd week (Kirmizibayrak and Boga, 2018). The higher results of the current study may be due to the fact that geese were reared in an intensive environment with a diet containing high protein and energy.

In a study, it was reported that the average BL of 10-12-week-old domestic geese was between $6.70 \pm 0.26$ $\mathrm{cm}$ and $7.24 \pm 0.02 \mathrm{~cm}$ (Saatci and Tilki 2007). This may mean that there is a variation within the native goose genotype. In addition, average beak length was found as $8.88 \pm 0.10 \mathrm{~cm}$ in a study conducted on native geese in Bangladesh (Islam et al., 2016). This situation may be caused by the difference in the goose breeds. However, it can be specified that the values are approximate.

The WL values found were higher than the values stated in 10-12-week-old native geese under breeder conditions (46.10 $\pm 1.63-48.80 \pm 0.37 \mathrm{~cm}$ ) (Saatci and Tilki 2007). This can be explained by the fact that 
geese in the present study had higher live weights.

In a study, average HD in geese was specified as $6.42 \pm 0.02 \mathrm{~cm}$ (Islam et al., 2016). In the current study, according to the treatment groups, this value was found as $4.21 \pm 0.03 \mathrm{~cm}, 4.19 \pm 0.03 \mathrm{~cm}$, and $4.20 \pm 0.03$ $\mathrm{cm}$, respectively for C, B, and M. These values were lower than the values of Islam et al., (2016). This situation may be caused by the genotype difference in the studies.

According to Fig. 6 BT was evaluated as a character to which special attention should be shown and has a determining feature in the studies.

Group $M$ showed a TI reaction for a shorter period when compared to groups $C$ and $B(P>0.05)$. This may be due to the fact that the mirror creates a crowd simulation without increasing the placement frequency. In addition, the mirror may have functioned for the geese to adapt to unexpected situations.

The productivity in poultry production has extraordinarily increased in the course of time. However, this increase in productivity has brought some hesitations. Today, consumers have questioned the trust on these foods. Factors such as food safety, environmental enrichment, and animal welfare in poultry production take place among the best methods for the elimination of such hesitations. Among them, environmental enrichment increases animal wealth, while it does not cause any negative effects on yield. These methods can also be benefited in goose breeding. In the current study, the effects of some objects used for environmental enrichment on Turkish native geese were investigated. The behavior of Turkish native geese changed positively without affecting negatively their yield levels. As a result, it can be expressed that geese are affected by environmental factors like other poultry and further studies for determining the environmental enrichment methods and objects that are required for goose breeding are required.

\section{Declarations}

\section{Funding}

Kirsehir Ahi Evran University Scientific Research Projects Commission had gave financial support to this Project (ZRT.A4.17.007).

\section{Conflicts of interest/Competing interests}

There is no conflict of interest between the all authors of present research.

\section{Ethics approval}

Approval was granted by the Kirsehir Ahi Evran University Animal Experiments Local Ethics Committee (27.01.2016-01/12).

\section{Consent to participate}


Not applicable

\section{Consent for publication}

Not applicable

\section{Availability of data and material}

All data are available via the corresponding author.

\section{Code availability}

Not applicable

\section{Authors' contributions}

All authors (A. Taskin, U. Karadavut, E. Dogan ana D. Ergun) contributed to the study conception and design. ED, DE and AT received data, AT, UK and DE planned the research and wrote the article. All authors read and approved the manuscript.

\section{Acknowledgments}

Kirsehir Ahi Evran University Scientific Research Projects Commission had gave financial support to this Project (ZRT.A4.17.007).

\section{References}

1. Akbas, A.A., Sari, M., Bugdayci, K.E., and Saatci, M., 2020. The effect of sex and slaughter age on growth, slaughter, and carcass characteristics in Lindovskaya geese reared under breeder conditions. Turkish Journal of Veterinary and Animal Sciences, 44, 1087-1092.

2. Belz, E.E., Kennell, J.S., Czambel, R.K., Rubin, R.T., and Rhodes, M.E.. 2003. Environmental enrichment lowers stress-responsive hormones in singly housed male and female rats. Pharmacology Biochemistry and Behaviour, 76 (3-4), 481-486.

3. Boz, M.A, Sarica, M., and Yamak, U., 2017. Production traits of artificially and naturally hatched geese in intensive and free-range systems: I. Growth traits. British Poultry Science, 58, 132-138. doi: 10.1080/00071668.2016.1261997

4. Boz, M.A., Oz, F., Yamak, U.S., Sarica, M., and Cilavdaroglu, E., 2019. The carcass traits, carcass nutrient composition, amino acid, fatty acid, and cholesterol contents of local Turkish goose varieties reared in an extensive production system. Poultry Science, 98(7), 3067-3080. doi: 10.3382/ps/pez125.

5. Branch, C.L., Kozlovsky, D.Y., and Pravosudov, V.V., 2015. Elevation related variation in aggressive response to mirror image in mountain chickadees. Behaviour, 152(5), 667-676. 
6. Ergun, D., Ergun, F., Taskin, A., and Karadavut, U,. 2020. In Cryopreservation of Goose (Anser anser) Sperm, Use of Diluents Containing 5\% DMSO. 5th International Anatolian Agriculture, Food, Environment and Biology Congress. Turkey, 268-276

7. Fanatico, A.C., Pillai, P.B., Emmert, J.L., and Owens, C.M., 2007. Meat quality of slow-growing chicken genotypes fed low-nutrient or standard diets and raised indoor or with outdoor access. Poultry Science, 86, 2245-2255.

8. Fernandes, D.P.B., Silva, I.J.O., Nazareno, A.C., Donofre, A.C., and Sevegnani, K.B., 2015. Recognition of colors of objects and food opposite chromaticities by broiler chicks. Arquivo Brasileiro de Medicina Veterinária e Zootecnia, 67(3). 873-881.

9. Gebhardt-Henrich, S.G., Pflug, A., Fröhlich, E.K.F., Käppeli, S., Guggisberg, D., Liesegang, A., and Stoffel, M.H., 2017. Limited associations between keel bone damage and bone properties measured with computer tomography, three-point bending test, and analysis of minerals in Swiss laying hens. Frontiers in Veterinary Science, 4, 128.

10. Islam, M.F., Mia, M.M., Rahman, M.A., and Bhowmik, N., 2016. Morphometric, productive and reproductive traits of indigenous goose of Bangladesh. Animal Genetic Resources, 59, 37-45.

11. Karadavut, U., and Taskin, A., 2014. Determination of Factors Affecting Poultry Meat Consumption in Kırşehir Province. Journal of Tekirdag Agricultural Faculty, 11(1), 37-43.

12. Karadavut, U., Taskin, A., and Genc, S., 2017. Comparison of growth curve models in Japanese quail raised in cages enriched with different colored lights. Brazilian Journal of Animal Science, 46(11), 839-846. Doi: 10.1590/S1806-92902017001100002

13. Kirmizibayrak, T., and Boga, B.K., 2018. Slaughter and Carcass Traits of Geese with Different Feather Colour and Gender. Brazilian Journal of Poultry Science, 20(4), 759-764.

14. Kokoszynski, D., Bernacki, Z., Grabowicz, M., and Stanczak, K., 2014. Effect of corn silage and quantitative feed restriction on growth performance, body measurements, and carcass tissue composition in White koluda W31 geese. Poultry Science, 93, 1993-1999.

15. NRC., 1994. Nutrient requirements of poultry. Ninth Revised Edition, National Academy Press, Washington.

16. Regmi, P., Smith, N., Nelson, N., Haut, R.C., Orth, M.W., and Karcher, D.M., 2016. Housing conditions alter properties of the tibia and humerus during the laying phase in Lohmann white Leghorn hens. Poultry Science, 95, 198-206.

17. Saatci, M., and Tilki, M., 2007. Zoometrical body measurements and their relation with liveweight in native Turkish geese. Turkish Journal of Veterinary and Animal Sciences, 31, 47-53.

18. Saatci, M., Arslan, C., Unal, Y., Tilki, M., and Aksoy, A.R., 2011. Effect of fattening length, sex and feather colour on growth and fattening performance in native Turkish geese. Eurasian Journal of Veterinary Sciences, 27, 183-189.

19. Schmid, A., 2011. The role of meat fat in the human diet. Critical Reviews in Food Science and Nutrition, 51, 50-66. 
20. Schmidt-Nielsen, K., 1997. Animal physiology: Adaptation and environment. Cambridge University Press, Cambridge, UK.

21. Szabone Willin, E., 1997. Changing of body measurements and the correlation of these with body weight from 0-16 weeks of age in geese. Allattenyesztes es Takarmanyozas, 46, 409-414.

22. Taskin, A., Ergun, F., Karadavut, U., and Ergun, D. 2020a. Effects of extenders and cryoprotectants on cryopreservation of duck semen. Turkish Journal of Agriculture - Food Science and Technology, 8(9), 1965-1970.

23. Taskin, A., Ergun, F., Karadavut, U., and Ergun, D. 2020b. In vitro Storage of Peking Duck Semen in Different Diluents at $+5^{\circ} \mathrm{C}$. Turkish Journal of Agricultural and Natural Sciences, 4, 1018-1025.

24. Taskin, A., Karadavut, U., and Cayan, H. 2018. Behavioural responses of white and bronze turkeys (Meleagris gallopavo) to tonic immobility, gait score and open field tests in free-range system. Journal of Applied Animal Research 46(1), 1253-1259. doi: 10.1080/09712119.2018.1495642

25. Tokita, M., Matsushita, H., and Asakura, Y., 2020. Developmental mechanisms underlying webbed foot morphological diversity in Waterbirds. Scientific Reports, 10, 8028. Doi: 10.1038/s41598-02064786-8

26. Tůmová, E., and Uhlírová, L., 2013. The evaluation of meat yield and physical properties in the Czech goose and the commercial hybrid the Novohradská goose. Maso International, 2, 133-138.

27. Van de Weerd, H.A., and Day, J., 2009. A review of environmental enrichment for pigs housed in intensive housing systems. Applied Animal Behaviour Science, 116, 1-20.

28. Yakan, A., Aksu Elmali, D., Elmali, M., Sahin, T., Motor, S., and Can, Y., 2012. Carcass and meat quality characteristics of white and multicolor geese under local breeder conditions. Kafkas Universitesi Veteriner Fakultesi Dergisi, 18, 663-670. Doi:10.9775/kvfd.2012.6238

29. Yildirim, M, and Taskin, A., 2017. The effects of environmental enrichment on some physiological and behavioral parameters of broiler chicks. Brazilian Journal of Poultry Science, 19, 355-62. doi: 10.1590/1806-9061-2016-0402

30. Taskin, A., and Karadavut, U., 2017. The effects of environmental enrichment objects on behaviors of Japanese quails at different cage stocking densities. Indian Journal of Animal Research, 51, 541548. Doi: $10.18805 /$ ijar.10772

\section{Figures}




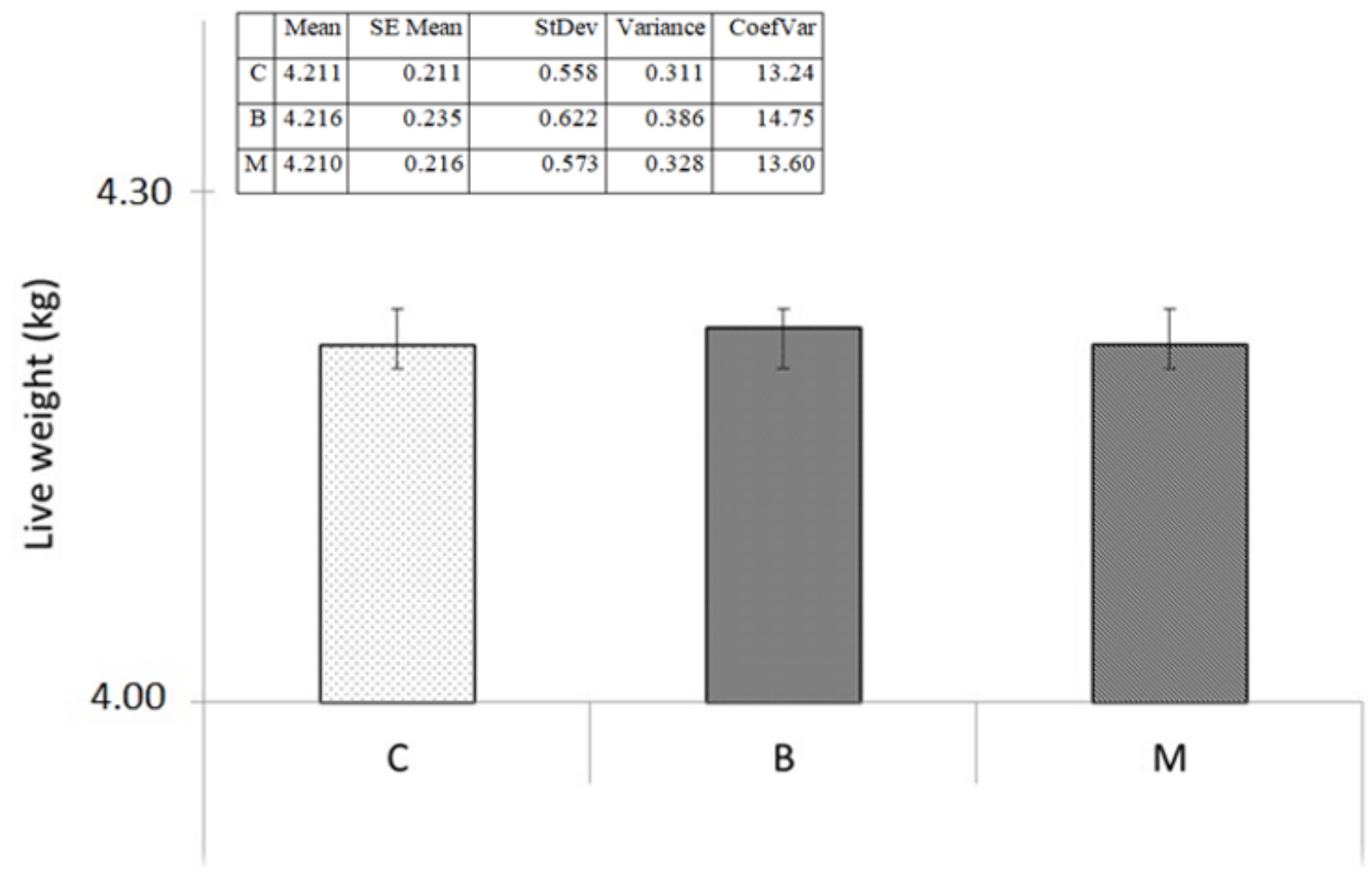

Figure 1

14th week LW and descriptive statistics of the groups. 


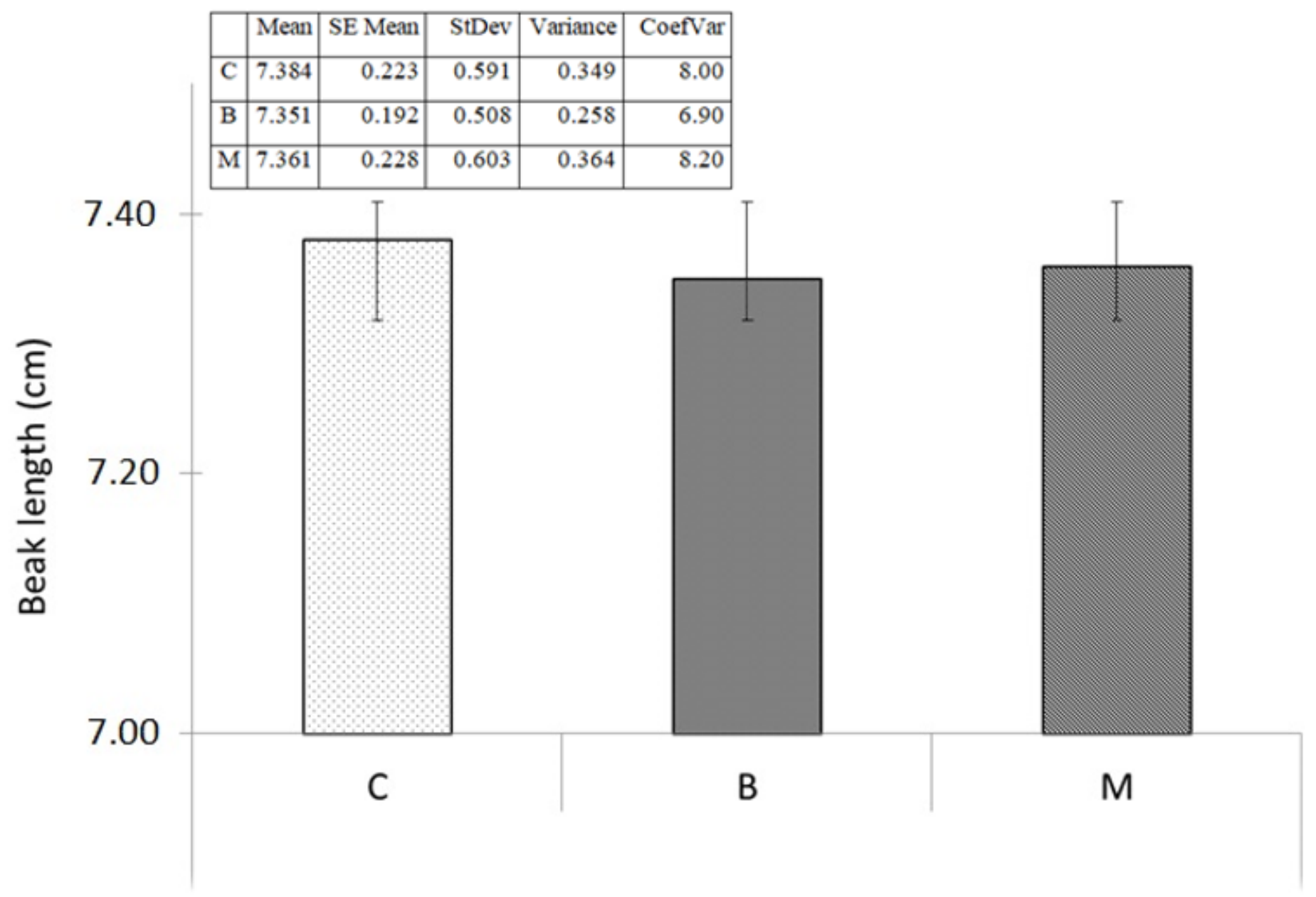

Figure 2

14th week BL and descriptive statistics of the groups. 


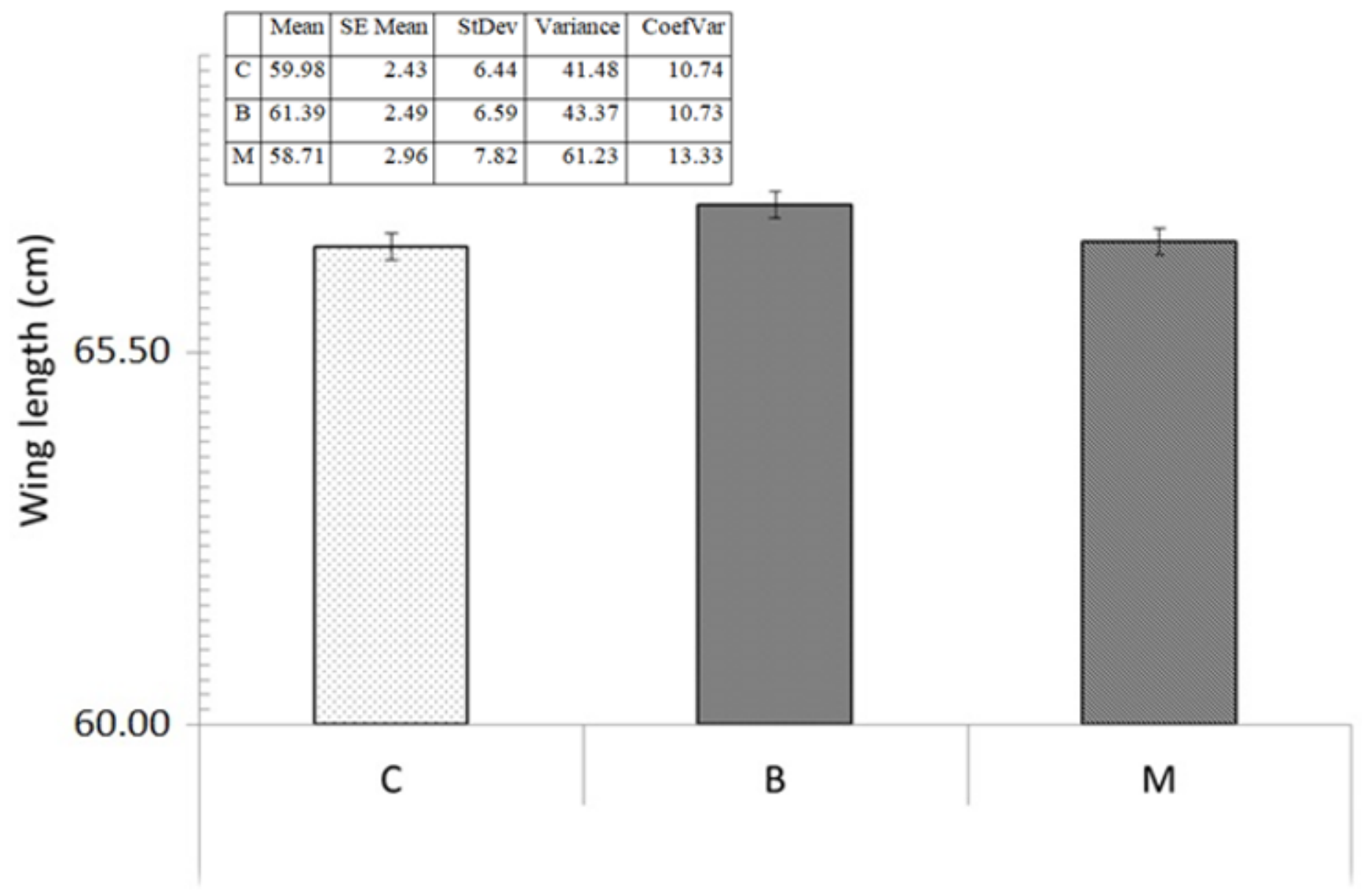

Figure 3

14th week WL and descriptive statistics of the groups. 


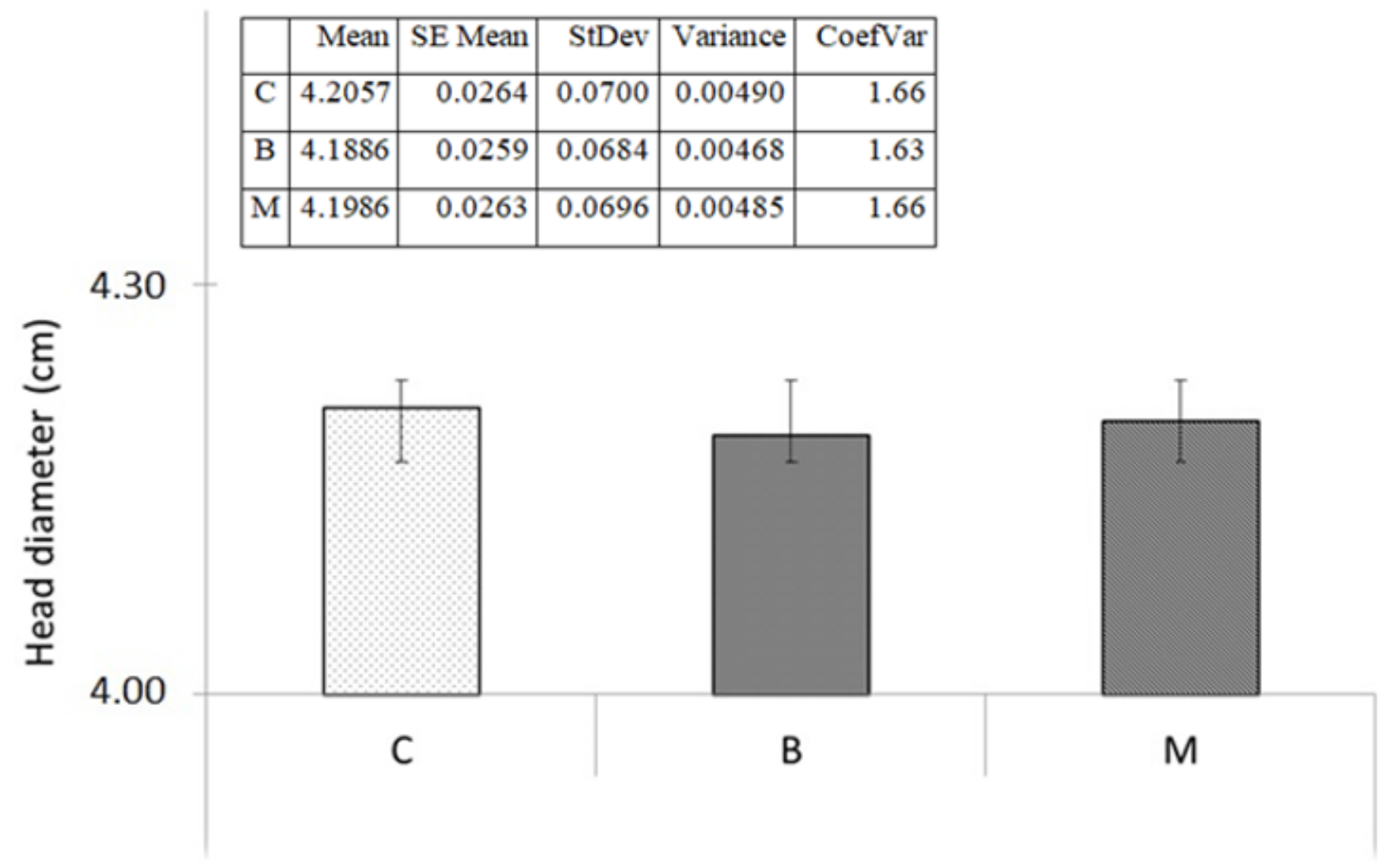

Figure 4

14th week HD and descriptive statistics of the groups. 


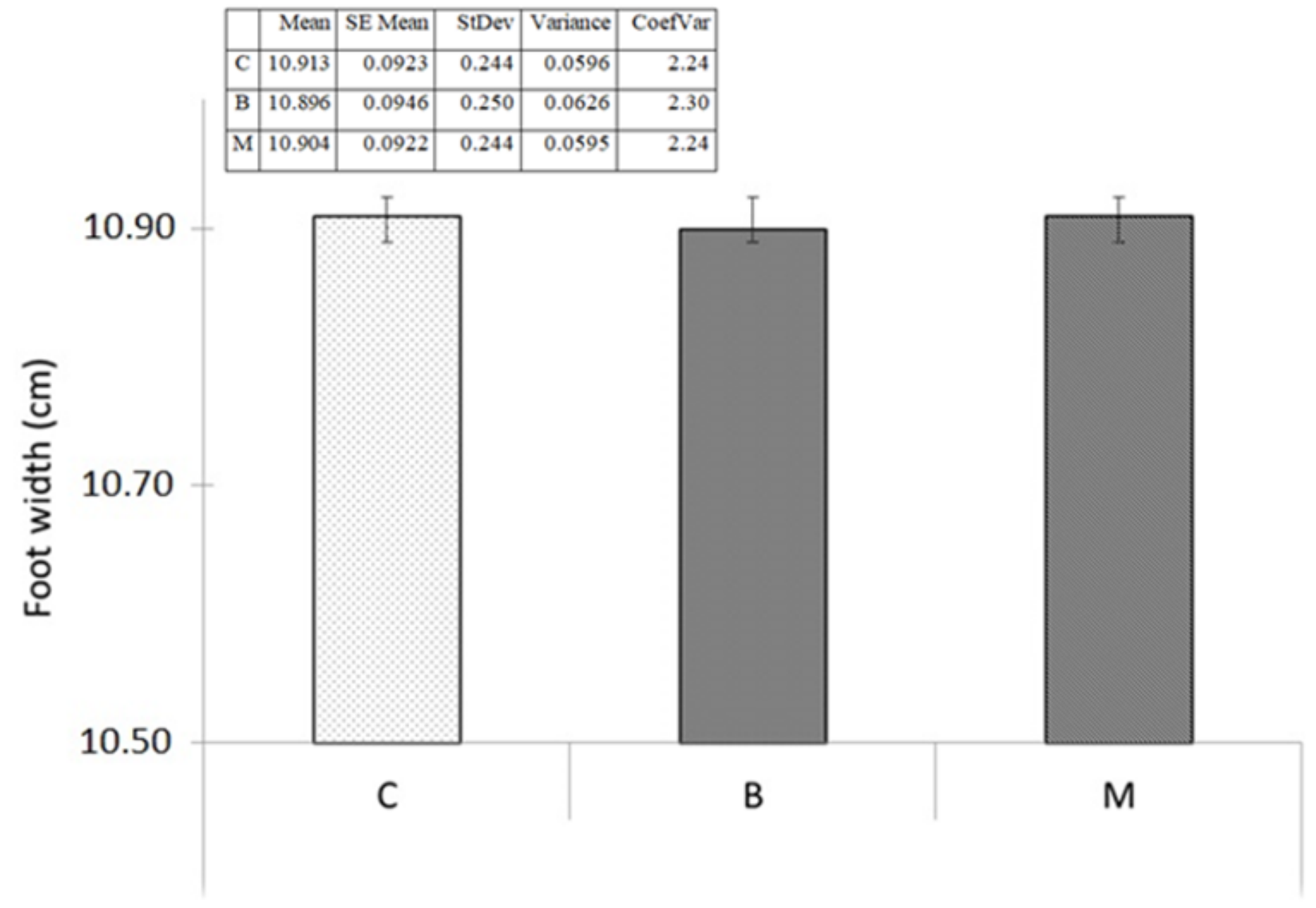

Figure 5

14th week FW and descriptive statistics of the groups.
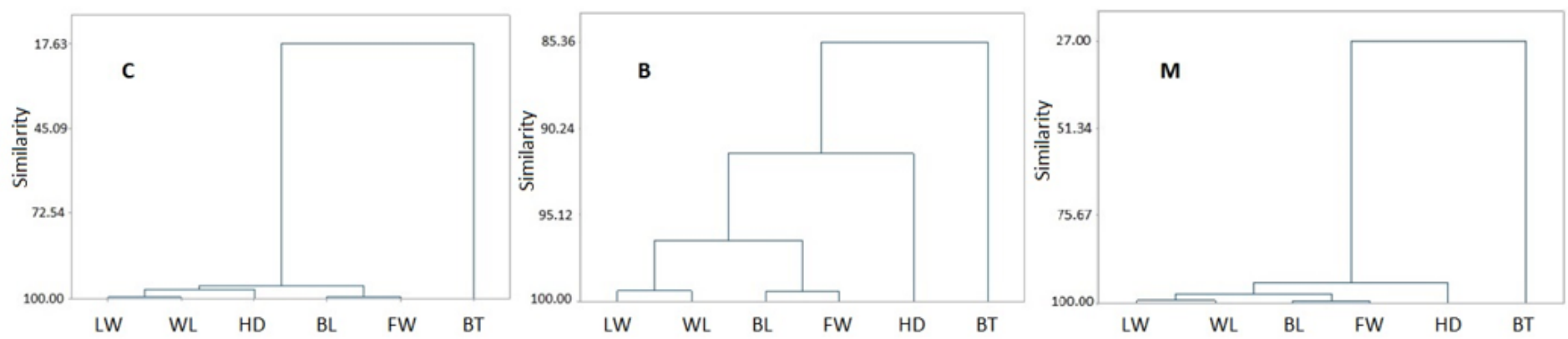

Figure 6

Cluster analysis of groups. 

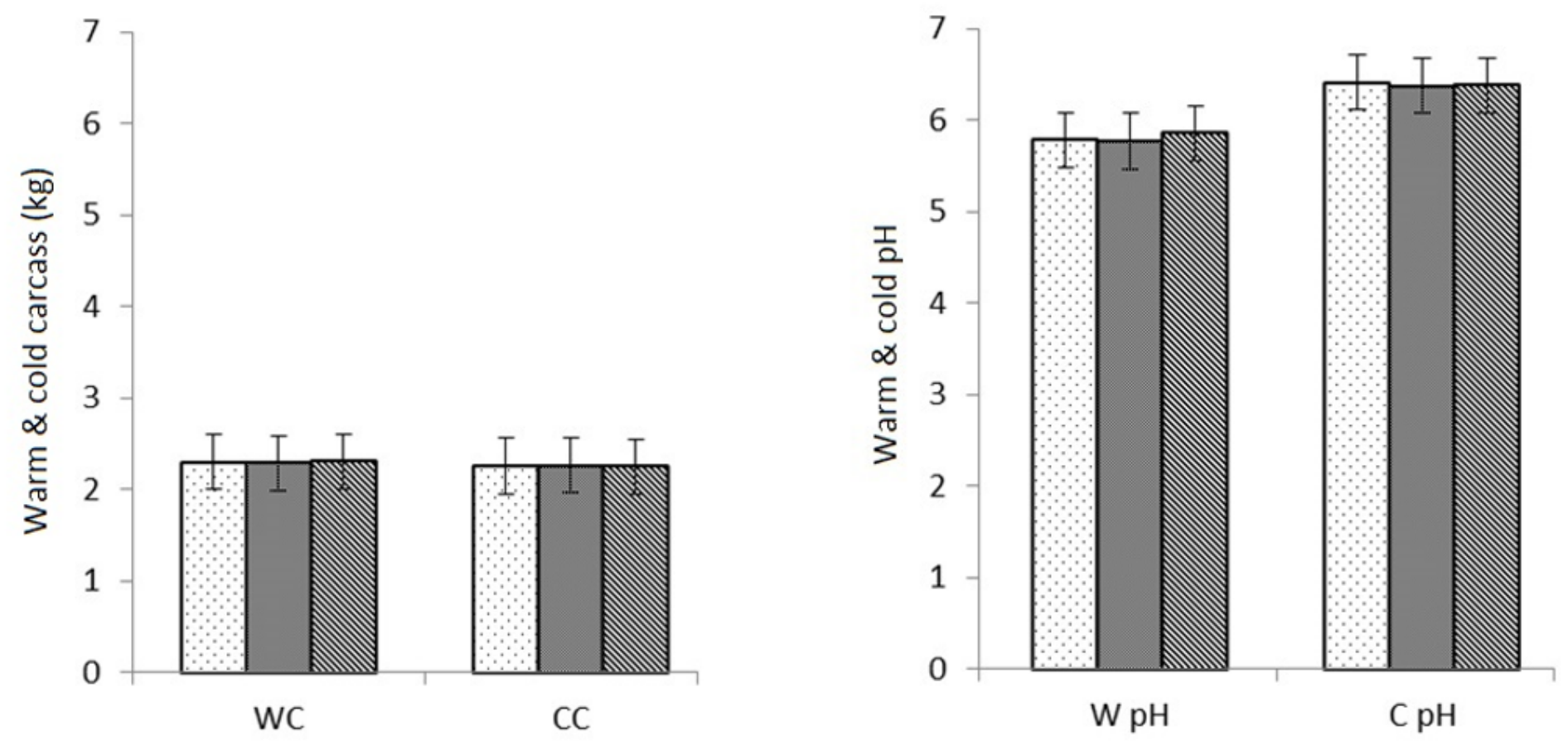

Figure 7

WC, $\mathrm{CC}, \mathrm{W} \mathrm{Ph}$ and $\mathrm{C} \mathrm{pH}$ values of groups.

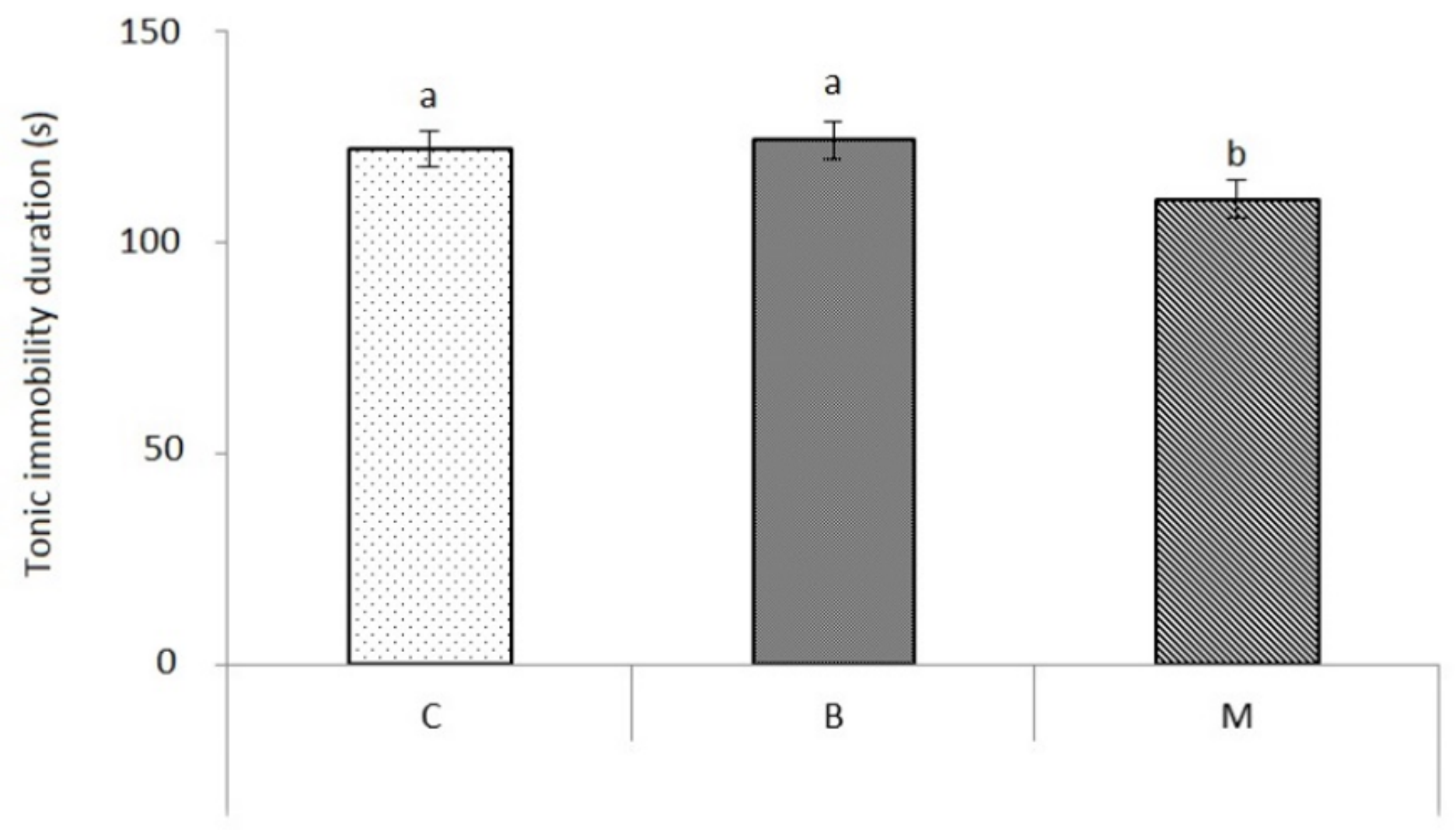

Figure 8

14th week TI durations of the groups 


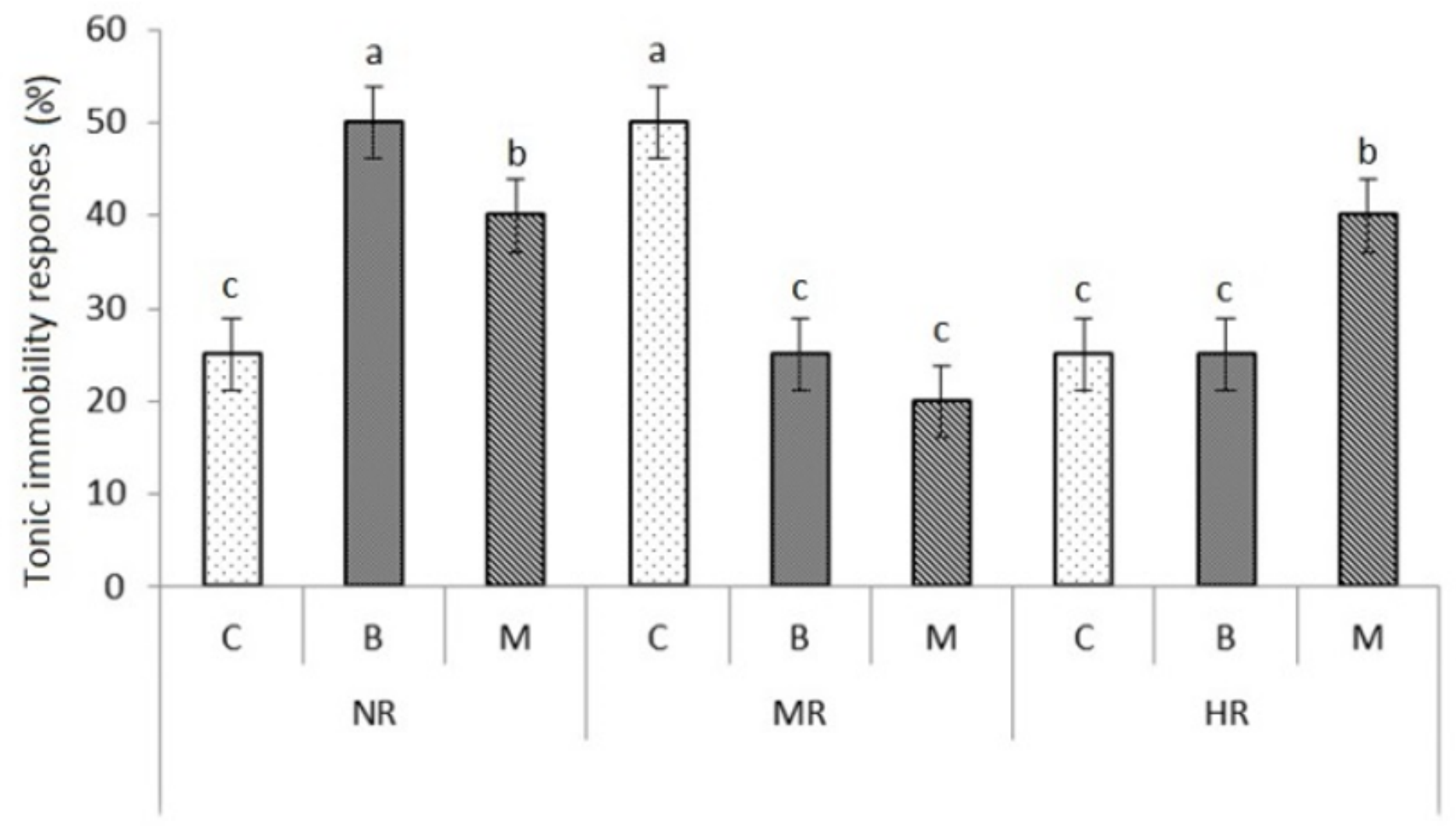

Figure 9

14th week TI reaction (NR), (MR) and (HR) values of the groups. 